\title{
THE
}

\section{A comparison of satellite-derived sea surface temperature fronts using two edge detection algorithms}

Yi Chang

Peter C. Cornillon

University of Rhode Island, pcornillon@uri.edu

Follow this and additional works at: https://digitalcommons.uri.edu/gsofacpubs

The University of Rhode Island Faculty have made this article openly available.

Please let us know how Open Access to this research benefits you.

This is a pre-publication author manuscript of the final, published article.

Terms of Use

This article is made available under the terms and conditions applicable towards Open Access Policy Articles, as set forth in our Terms of Use.

\section{Citation/Publisher Attribution}

Chang, Y., \& Cornillon, P. (2015). A comparison of satellite-derived sea surface temperature fronts using two edge detection algorithms. Deep Sea Research Part II: Topical Studies in Oceanography, 119, 40-47. doi: 10.1016/j.dsr2.2013.12.001

Available at: https://doi.org/10.1016/j.dsr2.2013.12.001

This Article is brought to you for free and open access by the Graduate School of Oceanography at DigitalCommons@URI. It has been accepted for inclusion in Graduate School of Oceanography Faculty Publications by an authorized administrator of DigitalCommons@URI. For more information, please contact digitalcommons-group@uri.edu. 


\title{
A comparison of satellite-derived sea surface temperature fronts using two edge detection algorithms
}

\author{
Yi Chang ${ }^{1}$, Peter Cornillon ${ }^{2}$
}

1. Institute of Ocean Technology and Marine Affaris, National Cheng Kung University, 1 University Road, Tainan, Taiwan.

2. Graduate School of Oceanography, University of Rhode Island, Narragansett, RI 02882, USA.

Corresponding author: Yi Chang

E-mail: yichang@mail.ncku.edu.tw

Tel: $+886-6-2575575$ ext. 31148

Fax: $+886-6-2753364$

$3^{\text {rd }}$ revision and submitted to Deep Sea Research 2, December ?, 2013. 


\section{Abstract}

1 Satellite-derived sea surface temperature (SST) fronts provide a valuable resource

2 for the study of oceanic fronts. Two edge detection algorithms designed specifically to

3 detect fronts in satellite-derived SST fields are compared: the histogram-based

4 algorithm of Cayula and Cornillon $(1992,1995)$ and the entropy-based algorithm of

5 Shimada et al. (2005). The algorithms were applied to four months (July and August

6 for both 1995 and 1996) of SST fields and the results are compared with SST data

7 taken by the M.V. Oleander, a container ship that makes weekly transits between New

8 York and Bermuda. There is no significant difference in front pixels found with the

9 Cayula-Cornillon algorithm and those found in the in situ (Oleander) data. Furthermore,

10 for strong fronts, with gradients greater than $0.2 \mathrm{~K} / \mathrm{km}$, the distribution of fronts found

11 with the Shimada et al. algorithm is quite similar to that of fronts found with the

12 Cayula-Cornillon algorithm. However, there are significant differences in the number

13 of weak fronts found. This is seen clearly in waters south of the Gulf Stream where the

14 gradient magnitude of fronts found is less than $0.1 \mathrm{~K} / \mathrm{km}$. In this region, the probability

15 that the Shimada et al. algorithm detects a front rarely falls below $4 \%$ while the other

16 two algorithms find fronts less than $1 \%$ of the time. These results raise the question of

17 exactly what qualifies as an SST front, a classic problem in edge detection. 
18 Keywords: edge detection, sea surface temperature front, satellite. 


\section{Introduction}

20 Oceanic fronts can be defined as relatively narrow zones in which the gradient of a

21 given property is large compared to its background gradient in the region. Although not

22 explicitly defined as gradients in the horizontal, or near horizontal, these are generally

23 the gradients that one thinks of in the context of fronts. Fronts often correspond to

24 boundaries between different water masses or to large shears in currents although other

25 processes may give rise to fronts as well; e.g., a boundary between different vertical

26 mixing regimes on the continental shelf. Of interest in this paper are enhanced

27 horizontal gradients of temperature, specifically, sea surface temperature (SST) fronts.

28 With the broad availability of satellite-derived SST fields, there has been significant

29 effort devoted to the development of front-detection algorithms - automated methods

30 for detecting fronts in these fields - and to the use of the resulting front data sets in

31 scientific investigations. Front-detection algorithms fall into several categories, three

32 of which are relevant here: gradient algorithms (Moore et al., 1997), histogram

33 algorithms (Cayula and Cornillon, 1992, 1995; CCA, referring to the Cayula-Cornillon

34 Algorithm, hereafter), and entropy algorithms (Vazquez et al., 1999; Shimada et al.,

35 2005; SEA, referring to the Shimada Entropy Algorithm, hereafter). These algorithms

36 have been applied to thermal fronts in marginal seas (Hickox et al., 2000; Wang et al., 
37 2001; Belkin and Cornillon, 2003) as well as open ocean regions (Ullman et al., 2007;

38 Belkin et al., 2009). Several studies have also presented new views of oceanic fronts in

39 coastal and regional seas, such as Ullman and Cornillon (1999) who applied the CCA

40 to the northeastern coast of the US, and Shimada et al. (2005) and Chang et al. (2006,

41 2010) who applied SEA to the Japanese coast and northern South China Sea.

42 Interestingly, the West Luzon Front detected by CCA in Belkin and Cornillon (2003)

43 and by SEA in Chang et al. (2010) was not detected by Wang et al. (2001) in their

44 application of a gradient based algorithm to SST fields of the northern South China Sea.

45 This suggests that the gradient based approach may not be appropriate for the detection

46 of SST fronts in regions of weak SST gradients (Chang et al., 2010).

47 When applying automated algorithms of front detection to satellite images, it is

48 important to verify these methods. Ullman and Cornillon (2000) used SST fronts

49 detected in along-track ship data to evaluate CCA detected fronts in satellite-derived

50 fields. Fronts were identified in the in situ data based on along-track SST gradients. In

51 this paper, we compare CCA and SEA detected fronts in satellite-derived SST fields

52 with one-another and with fronts detected from continuous temperature measurements

53 conducted from a merchant ship in transit between New York and Bermuda, the same

54 basic data set used by Ullman and Cornillon (2000). We do not include comparison 
55 with a gradient based algorithm applied to the satellite-derived SST fields because this

56 was dealt with in detail in Ullman and Cornillon (2000). The result of that analysis was

57 that the gradient based algorithm found false fronts at roughly twice the rate that CCA

58 did. 


\section{Data and methods}

60 Full resolution $(1.2 \mathrm{~km})$ July and August SST fields from both 1995 and 1996 were

61 used for this study. These fields were derived from the level $2 b$ (L2b)' Advanced Very

62 High Resolution Radiometer (AVHRR) data in the University of Miami/University of

63 Rhode Island (URI) archive with version 5.0 of the National Oceanic and Atmospheric

64 Administration (NOAA)/National Aeronautics and Space Administration (NASA)

65 Pathfinder algorithm (Smith et al. 1996). Data in the archive cover the waters off the

66 northeastern coast of the United States and the southeastern coast of Canada, east to

67 approximately $40^{\circ} \mathrm{W}$. Following retrieval to L2b, the 2 to 4 passes available per day

68 were manually navigated to within 1 pixel, $\sim 1.1 \mathrm{~km}$ at nadir. The fields were then

69 remapped to an equirectangular projection (L3) with $1.2 \mathrm{~km}$ pixel spacing at the image

70 center, $38^{\circ} \mathrm{N} 70^{\circ} \mathrm{W}$. Remapping from L2b was performed using the nearest neighbor

71 L2b pixel to the target L3 pixel. The study area used for this project (Fig. 1), $78^{\circ}$ to

$7263^{\circ} \mathrm{W}$ and $31^{\circ}$ to $43^{\circ} \mathrm{N}$, was extracted from these fields. Cloud removal was performed

73 using the URI multi-image cloud detection algorithm described in Ullman and

\footnotetext{
${ }^{1}$ We use the NASA designation for data processing levels:
}

http://science.nasa.gov/earthscience/earth-science-data/data-processing-levels-for-eosdis-data-products/. 
74 Cornillon (1999). Detection of fronts in declouded SST images was performed using

75 both the CCA and SEA methods. Brief descriptions of these are given below. More

76 detailed descriptions are available in the original references (Cayula and Cornillon,

77 1992, 1995 for CCA; Vazquez et al., 1999 and Shimada et al., 2005 for SEA).

$78 \quad 2.1$ Front Detection Using Satellite-Derived Data

79 The Cayula-Cornillon algorithm (CCA) used in this study is the multi-image version

80 of the original multi-image edge detection algorithm developed at URI. In the first step,

81 the SST fields are median filtered with a $3 \times 3(3.6 \times 3.6 \mathrm{~km})$ kernel to reduce noise in the

82 field. This provides for a sharper separation of peaks corresponding to different water

83 masses in the histograms used in the next step. Reducing the noise in the image is also

84 beneficial in the contour following step. In the second step, the single image edge

85 detector (SIED) is applied to each image in the time series. The SIED performs a set of

86 statistical tests on histograms of the temperature field in a moving $n \times n(32 \times 32$ in this

87 study) pixel window to identify candidate front pixels. It then descends to the pixel

88 level and follows contours identified by the candidate front pixels. Segments shorter

89 than $m$ (10 in this study) pixels are subsequently eliminated from consideration. A

90 second pass is then made over the images in the archive. First a zero-one image,

91 initialized to zero, is formed in which each pixel flagged as a front pixel in any image 
92 within $n$ (60 in this study) hours of the given image, excluding the image of interest, is

93 set to one. (It is important to note that the window used here does not exclude shorter

94 time scale fronts; any front found in any of the adjacent images is included.

95 Furthermore, this step is used to 'help' the algorithm find fronts in areas partially

96 contaminated by clouds, it does not eliminate fronts.) The resulting image is then

97 thinned, based on the local SST gradient, to lines one pixel wide. In the last step, the

98 SIED algorithm is applied a second time to each image in the archive, but this time it

99 uses the thinned persistent fronts associated with that image in the contour following

100 step along with candidate pixels found in the analysis of histograms in the image. Fig.

$1012 \mathrm{~b}$ shows fronts resulting from this procedure for the AVHRR-derived SST field shown

102 in Fig. 2a.

103 The Shimada et al. algorithm is specifically designed for finer-scale front detection

104 at the full image resolution of $1.2 \mathrm{~km}$ (Shimada et al., 2005). As typically employed,

105 the original SST fields are not filtered prior to application of this algorithm. However,

106 for comparison with CCA, SEA has been applied to both the original data, as is

107 normally done, and to the $3 \times 3$ median filtered version of the data. Edge detection

108 begins with an estimate of the Jensen-Shannon divergence in SST in two $5 \times 5$ pixel

109 subwindows in four directions (shown in Fig. 3 of Shimada et al., 2005). A composite 
110 matrix is built from the four Jensen-Shannon divergences, and the maximum value is

111 taken as the final divergence value to be assigned to each pixel. If this value exceeds

1120.6 then the pixel is designated a front pixel. Finally, a thinning algorithm is applied to

113 obtain pixel wide frontal segments. The results, again for the SST field in Fig. 2a, are

114 shown in Fig. 2c for the unfiltered SST field and in Fig 2e for the $3 \times 3$ median filtered

115 field. However, in order to compare this with CCA derived fronts, frontal segments

116 shorter than 10 pixels are removed from further comparisons. These fronts are shown

117 in Figs. 2d and 2f. Following front-detection, the SST gradient was calculated at each

118 front pixel resulting from each of the two algorithms using the Prewitt operator to

119 obtain the latitudinal and longitudinal gradient components. The gradient magnitude,

$120\left|\mathrm{~T}_{\mathrm{s}}\right|$ where $\mathrm{T}_{\mathrm{s}}$ is SST, was determined from the Prewitt components.

$121 \quad 2.2$ Processing of Ship Measurements

122 Comprehensive validation of the Cayula-Cornillon algorithm for satellite-derived

123 SST images using in situ data is described by Ullman and Cornillon (2000). In this

124 study we compare SEA and CCA detected fronts with fronts detected in continuous

125 ocean temperature measurements made from the container vessel M.V. Oleander

126 (Oleander in the remainder), which regularly navigates between Port Elizabeth, NJ and

127 Bermuda. The mean ship track is superimposed on Fig. 1 (black line). The Oleander 
128 temperature data were measured by a flow system at a depth of between 5 and $6 \mathrm{~m}$

129 sampled every $15 \mathrm{~s}$, a corresponding spatial sampling of approximately $110 \mathrm{~m}$ at a

130 ship speed of 15 knots. For comparison with the AVHRR data, the Oleander data were

131 averaged to a $1.2 \mathrm{~km}$ spacing along the ship's track. SST fronts in the Oleander data

132 were identified by their along-track gradient as described in Ullman and Cornillon

133 (2000). Specifically, an along-track location was defined as a front if one of two

134 criteria was met. (1) The SST gradient magnitude exceeded $0.2 \mathrm{~K} / \mathrm{km}$ or (2) SST

135 gradient magnitude exceeded $0.1 \mathrm{~K} / \mathrm{km}$ and the gradient magnitude at the along-track

136 location was five times larger than the mean gradient magnitude averaged over a 70

$137 \mathrm{~km}$ section centered on the point of interest - the definition of a front used by Fedorov

138 (1986). For the comparisons undertaken in this study, only satellite-derived SST fronts

139 intersecting a ship track within $6 \mathrm{~h}$ of the passage of the ship were selected for further

140 analyses. 


\section{Results}

$142 \quad 3.1$ SST Front Probability and Mean Gradient Maps

143 Monthly composite maps of front probability were produced from the fronts

144 detected in the individual satellite-derived images for June to August in both 1995 and

145 1996. Front probability at a pixel is defined as the number of times the pixel was

146 designated as a front pixel in the period considered divided by the number of times the

147 pixel was clear in the same period. Fig. 3 shows the CCA (Fig. 3a) and the SEA (Fig.

148 3b, c and d) SST front probabilities for August 1995. The CCA (3a) front probability

149 map shows several frontal bands between Cape Hatteras (white arrow) and Georges

150 Bank (yellow arrow). Most of these bands are approximately parallel to the $100 \mathrm{~m}$

151 isobath with front probabilities as high as $11 \%$. In contrast, front probabilities in the

152 unfiltered $\mathrm{SEA}^{2}$ map (3b) are everywhere substantially larger, up to $16 \%$ at some

153 locations on the continental shelf, than those in the CCA-derived field. SEA front

2 'Unfiltered' here refers to the SST fields from which the fronts were derived. It does not refer to filtering, or the lack thereof, of the probability fields. 'Filtered' SEA fields refers to the application of a $3 \times 3$ median filter to the SST fields prior to the application of SEA. This convention will be used througout this manuscript. 
154 probabilities obtained after eliminating front segments less than 10 pixels long from

155 the unfiltered data (Fig. 3c), although less than the corresponding probabilities in the

156 full SEA field (expected since a significant number of front pixels have been removed

157 from the data), are still higher than the corresponding CCA probabilities. This is

158 especially evident across much of the southern part of the study area; e.g., the area

159 indicated by the red arrow. In contrast, the front probabilities for the filtered fields

160 with front segments shorter than 10 pixels removed (Fig. 3d) are quite different than

161 the unfiltered version (Fig. 3c). Specifically, the filtered data show a significant

162 decrease in front probability on the shelf when compared to the unfiltered probabilities

163 and a significant increase in waters seaward of the Gulf Stream. In both cases - the

164 increase in front probability seaward of the Gulf Stream and its decrease shoreward -

165 well know structures in this region, such as the Gulf Stream and the Shelf Break front

166 clearly evident in the CCA probability field (Fig. 3a) and to a lesser extent in the

167 unfiltered SEA field (Fig. 3c), tend to be all but eliminated in the filtered field (Fig. 3d).

168 In light of this, the focus of the remainder of this manuscript will be on comparisons of

169 unfiltered SEA probabilities with CCA probabilities and front locations in the in situ 170 data.

171 Fig. 4a shows the mean SST gradient magnitude, $\left|\nabla T_{s}\right|$, for August 1995 at CCA 
172 detected front locations and Figs. $4 \mathrm{~b}$ and $\mathrm{c}$, the corresponding SEA fields. These mean

173 fields were obtained only from gradient values when a front was present. Specifically,

174 if a front was detected by CCA at location $\mathrm{x}, \mathrm{y}$ in images $\mathrm{A}$ and $\mathrm{B}$, but not in image $\mathrm{C}$,

175 only $\left|\nabla \mathrm{T}_{\mathrm{s}}\right|$ from images $\mathrm{A}$ and $\mathrm{B}$ were used when calculating the mean at $\mathrm{x}, \mathrm{y}$. In most

176 locations, the CCA front $\left|\nabla \mathrm{T}_{\mathrm{s}}\right|$ is larger than the corresponding SEA value. This is

177 because SEA finds more fronts, many of which tend to be weaker (as will be shown

178 shortly and discussed in more detail in Section 4) than those found by CCA, thus

179 reducing the mean value. The same behavior is observed when comparing the full SEA

180 detected $\mid \nabla \mathrm{T}_{\mathrm{s}} \mathrm{I}$ field (Fig. 4b) with that obtained from the reduced SEA data set (Fig. 4c);

181 i.e., after the removal of short and presumably weaker frontal segments. The CCA front

$182\left|\nabla \mathrm{T}_{\mathrm{s}}\right|$ map shows that mean fronts in the study area tend to be stronger, with values

183 approaching $0.3 \mathrm{~K} / \mathrm{km}$, along the shelf-break than elsewhere in the region. The largest

184 values occurred on the southeastern flank of Georges Bank. The mean front $\left|\nabla \mathrm{T}_{\mathrm{s}}\right|$

185 values along the shelf-break are consistent with those found by Ullman and Cornillon

186 (1999) for the climatological summer, July through September, based on data from

1871985 through 1996. Although the SEA front IVT $\mid$ map (Fig. 4b) shows similar patterns

188 on the periphery of Georges Bank, with the strongest values $>0.3 \mathrm{~K} / \mathrm{km}$, the pattern in 
190 CCA and SEA front gradient fields. Frontal bands clearly seen in the CCA composite

191 are only vaguely discernible in the SEA composite; e.g., along the northern and

192 southern boundaries of the Gulf Stream (white arrows in Fig. 4a, b). However, the SEA

193 front $\left|\nabla T_{\mathrm{s}}\right|$ map generated with short fronts eliminated (Fig. 4c), is more similar to the

194 CCA map than is the SEA map based on all detected fronts. This suggests that much of

195 the difference in the performance of the two edge detection algorithms is related to

196 short, weak front segments found by the SEA but not by CCA. 
202 in time were averaged. Cloud contaminated pixels were not included in the average.

203 Given that AVHRR passes are separated by approximately 12 hours this results in a

204 value at virtually all Oleander locations (with temporal and spatial sampling of $15 \mathrm{~s}$

205 and $110 \mathrm{~m}$, respectively), cloud cover permitting. The large scale changes in SST are

206 well represented in both data sets shoreward of $\sim 600 \mathrm{~km}$ - both see the very large

207 change in SST at the shelf-break, $200 \mathrm{~km}$ from New York, and the somewhat more

208 gentle increase at approximately $450 \mathrm{~km}$ associated with the shoreward edge of the

209 Gulf Stream. However, seaward of $\sim 630 \mathrm{~km}$ there is a notable difference in the trends.

210 SST in the Oleander record decreases rather abruptly at $\sim 630 \mathrm{~km}$, corresponding to the

211 seaward, or southern, edge of the stream, and then remains relatively constant at about

$21222^{\circ} \mathrm{C}$ for the remainder of the transect, In contrast, AVHRR SSTs decrease at a very

213 nearly constant rate from their peak of $26^{\circ} \mathrm{C}$ in the Gulf Stream $(\sim 500 \mathrm{~km})$ to $\sim 20^{\circ} \mathrm{C}$

214 toward the end of transect. Given that the Oleander data is warmer than the AVHRR

215 data in this region, it is unlikely that the difference is due to the difference in depth at 
216 which the observations are made - 5 to $6 \mathrm{~m}$ for the Oleander and the top $10 \mu \mathrm{m}$ for

217 AVHRR - since one would expect deeper waters to be slightly cooler than surface

218 waters, not warmer. The more likely explanation is that high, thin clouds or small,

219 unresolved clouds are depressing the satellite-derived SST values seaward of the

220 southern edge of the Gulf Stream. A significant increase in cloud cover south of the

221 stream is evident in the images for 2-4 June (not shown) supporting this view.

222 Although pixels contaminated in this way are not likely to introduce false fronts in the

223 CCA results and most likely not in the SEA results, they are likely to depress SST

224 retrievals.

225 The locations of fronts found with the three different methods (SEA fronts are only

226 those with at least 10 pixels per front segment) are also indicated in Fig. 5. Consistent

227 with Figs. 2 and 3, significantly more fronts are found by SEA than CCA. Significantly

228 more fronts are also found in the Oleander data than by CCA, but these, as with the

229 fronts located by CCA, tend to cluster in regions of large SST gradients while the SEA

230 fronts tend to be more uniformly distributed. Note that no fronts are found seaward of

231 about $900 \mathrm{~km}$ by CCA or in the Oleander data while there is a significant number

232 found by SEA. Fig. 6 is a statistical summary in histogram form of the location of

233 fronts, as defined by the various algorithms, along the Oleander track for all ship 
234 sections in June and August of 1995 and 1996. Histogram bins correspond to $20 \mathrm{~km}$

235 along-track sections, $\sim 16$ AVHRR pixels. A peak located approximately $200 \mathrm{~km}$ from

236 New York is evident for all three algorithms (Figures4a-c). The location of these peaks

237 corresponds to the location of the $200 \mathrm{~m}$ isobath and the associated shelf-break front;

238 i.e., to the high gradient region evident at $200 \mathrm{~km}$ in Fig. 5. There are also two

239 relatively well-defined peaks at approximately $420 \mathrm{~km}$ and $530 \mathrm{~km}$ in the Oleander

240 histogram. These correspond to the mean positions of the in-shore edge of the Gulf

241 Stream, sometimes referred to as the 'North Wall', and the southern edge of the stream,

242 respectively; the approximate location of the high gradient regions seen in the Oleander

243 data at $\sim 450 \mathrm{~km}$ and $\sim 630 \mathrm{~km}$ in Fig. 5. The correspondence is not exact because of the

244 lateral displacement of the Gulf Stream. There is a suggestion of peaks in the same

245 locations in the CCA and SEA data. However, there are a number of other peaks in the

246 SEA data that do not correspond to any in the Oleander data confounding the

247 interpretation of the Gulf Stream peaks. The clearest difference between the histograms

248 is in the larger number of SEA fronts compared with both CCA and Oleander fronts in

249 all bins. This is discussed in more detail in the next section. 


\section{Discussion and Conclusion}

251 Comparisons of along-track fronts discussed in the previous section reveal clear

252 differences between the satellite and the in situ data. Table 1 shows the results of an

253 analysis of Variance (ANOVA) information table testing the number of front pixels per

$25420 \mathrm{~km}$ bin detected by the in-situ, CCA, and SEA algorithms. There is a significant

255 difference between the numbers of fronts in the three datasets $(p<0.05)$. We therefore

256 compared the difference in numbers between pairs of datasets. For the Oleander-CCA

257 pair, there are no obvious differences; the null hypothesis cannot be rejected. However,

258 the numbers of front pixels are significantly different between the Oleander and SEA

259 and between the CCA and SEA, datasets.

260 The ANOVA tests establish the statistical significance of the difference in the mean

261 number of fronts per bin between SEA and CCA, and SEA and in situ, but not in the

262 shapes of the distributions. In fact, the increased number of detected fronts in the SEA

263 data appears to be fairly uniformly distributed along the Oleander track. Specifically,

264 the SEA histogram (Fig. 6c) decreases from a maximum at $200 \mathrm{~km}$, the shelf-break

265 front, to approximately $600 \mathrm{~km}$, seaward of which it is close to flat at about 90 detected

266 front pixels per $20 \mathrm{~km}$ bin, while seaward of $600 \mathrm{~km} \mathrm{CCA}$ and Oleander histogram

267 values (Figs. 6a \& b) are, on average, less than 10 detected fronts per bin. The 80 front 
268 difference is slightly smaller than, but close to, the difference, approximately 100

269 fronts, between the height of the shelf-break peak at $200 \mathrm{~km}$ in the SEA histogram (220

270 fronts) and that in the Oleander histogram (120 fronts). This suggests a background

271 level of front detection for the entropy algorithm of about $8 \%$; there are on average 80

272 cloud free pixels for the four month study period at each $(1.2 \mathrm{~km})$ location along the

273 Oleander track seaward of $600 \mathrm{~km}$ and there are 16 AVHRR pixels (and along-track

274 Oleander samples) in each $20 \mathrm{~km}$ bin yielding a total of approximately 1300 clear

275 pixels in each bin. This results in a probability on the order of 90/1300 (approximately

$2767 \%$ ) close to the values evident in Fig. 3c for this portion of the track. In fact, the

277 general differences in the SEA probability distribution (Fig. 3c) from the CCA

278 distribution (Fig. 3a) are consistent with the argument presented above for a relatively

279 flat background detection rate along the Oleander track.

280 In the previous paragraphs we have shown that there is a relatively uniform

281 background of SEA detected fronts to which are added fronts associated with major

282 features from the shelf to the outer edge of the Gulf Stream. In Section 3 we also

283 suggested that the fronts seen seaward of the Gulf Stream tend to be weak and likely

284 short. Here we revisit these observations. Ullman and Cornillon (2000) suggest that the

285 error rate in CCA front detection is $>40 \%$ when the temperature gradient is $<0.1 \mathrm{~K} / \mathrm{km}$ 
286 but falls rapidly with increasing SST gradient magnitude. Comparing the CCA gradient

287 map (Fig. 4a) with the SEA map based on eliminating short fronts (Fig. 4c), it is clear

288 that strong SST fronts, $>0.2 \mathrm{~K} / \mathrm{km}$, those along the shelf-break especially in the vicinity

289 of Georges Bank are well represented in both fields. This is similar to the results of

290 Ullman and Cornillon (2000) that front pixels with high $\left|\nabla \mathrm{T}_{\mathrm{s}}\right|$ are well defined.

291 However, pixels with gradients about $0.1 \mathrm{~K} / \mathrm{km}$ are clearly seen in offshore waters in

292 the SEA composite maps (Fig. 4b, c) but are not found in the CCA results (Fig. 4a). We

293 further investigated the spatial distribution of front pixels detected by CCA and SEA in

294 the single image shown in Fig. 7. CCA and SEA detected frontal segments (Fig. 7a and

295 b) correspond well in the Gulf Stream and along the shelf-break around Georges Bank.

296 However, SEA found many more frontal segments in the study area (Fig. 7b, with

297 fronts of $<10$ pixels omitted) than the CCA algorithm. When frontal segments from

298 both algorithms are superimposed (Fig. 7c), it is clearly seen that CCA frontal

299 segments (blue lines) are mainly distributed in coastal waters. In contrast, the SEA

300 segments (red lines) are evident throughout the image with a slightly higher density on

301 the shelf than in Slope, Gulf Stream or Sargasso Sea waters. This is consistent with the

302 number of fronts found along the track of the Oleander discussed in Section 3. Also

303 note that the SEA frontal segments tend to be substantially shorter on average than the 
304 CCA segments.

305 Following Ullman and Cornillon (2000), we also examine the error rate in detection

306 of SST fronts by CCA and SEA compared with the in situ data. False front errors occur

307 if the ship was at the location of an AVHRR front within 6 hours of the AVHRR image

308 time and a front was not found in the ship data. The error rates for each of the two

309 satellite-based algorithms are shown in Fig. 8 as a function of the SST gradient

310 associated with the front. The results for CCA compare well with those of Ullman and

311 Cornillon (2000). They are also consistently lower than the corresponding error rate for

312 SEA with the fractional discrepancy increasing substantially with SST gradient.

313 So why might the entropy algorithm (SEA) find more fronts than the histogram

314 algorithm (CCA) or the gradient algorithm applied to the in situ data? Initially, one

315 might think that the main reason for the discrepancy relates to the preprocessing of the

316 SST fields, specifically, to the median filtering of the fields. However, a comparison of

317 front probabilities obtained from SEA applied to the filtered SST fields with those

318 obtained from SEA applied to the unfiltered fields and to those obtained from CCA

319 suggest that this is not the case. Specifically, CCA tends to find fronts preferentially on

320 the continental shelf relative to waters seaward of the Shelf Break while SEA applied

321 to the filtered SST fields finds just the opposite, it finds fronts preferentially in waters 
323 discussed in some detail in previous sections, tends to find fronts preferentially on the

324 shelf as did CCA although at a much higher density. Other factors that might contribute

325 to the entropy algorithm finding more fronts than the CCA and in situ algorithms are:

326 (1) The size of the region examined by the algorithms (SEA vs. CCA): CCA identifies

327 two populations in $32 \times 32$ pixel histograms and uses the boundary pixels between

328 these populations to begin contour following. This means that if there are more

329 than two distinct populations in the window, the algorithm will miss fronts. The

330 fronts found will tend to be those between the largest two populations. The entropy

331 algorithm operates on $5 \times 5$ pixel subwindows, hence it is not constrained to the

332 same extent. The gradient algorithm applied to the in situ data used an even smaller

333 kernel.

334 (2) The effect of clouds on the retrieval of fronts (SEA vs. CCA, and SEA and CCA vs.

335 in Situ): As noted earlier, the histogram of SST fronts for the Oleander data (Fig. 6a)

336 shows two peaks associated with the Gulf Stream, one corresponding to the

337 northern edge at $\sim 400 \mathrm{~km}$ and one to the southern edge at $\sim 520 \mathrm{~km}$ and then it

338 drops precipitously from between 50 and 60 counts to 20 counts after which it is

339 relatively flat. Over the same region the CCA and SEA histograms decrease 
340 relatively smoothly from their values at $280 \mathrm{~km}$ to their values at $500 \mathrm{~km}$ after

341 which they too are relatively flat. There is a corresponding decrease in the percent

342 of pixels identified as 'clear' by the Pathfinder algorithm (not shown) from 280 to

$343500 \mathrm{~km}$. This increase in cloud cover is likely the cause of the differences in

344 numbers of fronts found by the different algorithms. Because the CCA operates on

$34532 \times 32$ pixel histograms and requires at least 100 clear pixels to perform the

346 histogram analysis and because it requires fronts to be at least 10 pixels long, its

347 performance decreases as cloud cover increases; i.e., the algorithm will miss fronts

348 in small clear regions. The SEA, which operates on smaller regions, is less

349 susceptible to this problem hence will find relatively more fronts than the CCA as

350 the cloud cover increases. The in situ algorithm does not depend on cloud cover at

351 all although a match-up is not attempted if the satellite-data are not clear in the

352 vicinity of the pixel of interest.

353 (3) The dimensionality of the data (SEA and CCA vs. in situ): Both CCA and SEA

354 operate on two-dimensional fields while the in situ algorithm operates on a line.

355 The two dimensionality of satellite-derived SST fields allows for a weaker gradient

356 or temperature threshold (depending on the algorithm) than that for the gradient

357 algorithm applied to the one dimensional data; i.e., the $2 \mathrm{~d}$ algorithms incorporate 
358 information from the second dimension in the detection of fronts.

359 In conclusion, the entropy algorithm finds many more weaker and likely shorter,

360 fronts than the histogram or the in situ gradient algorithms. Although many of these

361 fronts are likely real, the large number of weak fronts tends to mask the stronger fronts

362 in statistical analyses of front distribution. This problem might be addressed by

363 applying a filter to the SEA fronts; e.g., filtering on length, as we did here, and/or on

$364 \mid \nabla \mathrm{T}_{\mathrm{s}} \mathrm{l}$. The difficulty with applying filters, especially on the gradient, is what to use as a

365 threshold. This is one of the advantages of the histogram algorithm; it is relatively

366 insensitive to the gradient. In the end, the appropriate algorithm to use will depend on

367 the application, specifically, on what is considered to be a front for the application. The

368 histogram algorithm was designed to find long fronts separating two relatively large

369 water masses, fronts that are thought to be dynamically important; i.e., to extend

370 deeper in the water column than short, weak fronts. The latter may, however, be of

371 significance in biological or chemical studies and of indicators of some submesoscale

372 ocean structures.

374 Acknowledgements

375 This study was supported by a research grant (NSC96-2917-I-019-102) from the 
376 National Science Council, Taiwan. Salary support for P. Cornillon was provided by the

377 state of Rhode Island and Providence Plantations. The authors wish to thank Prof.

378 Hiroshi Kawamura, Dr. Futoki Sakaida, and Dr. Teruhisa Shimada of Tohoku

379 University, Japan for their technical support and advice and Dr. Igor Belkin of the

380 University of Rhode Island, USA for helpful advice on this manuscript.

381 


\section{Figure captions:}

Table 1: ANOVA table for the number of fronts detected by the Oleander, CCA and SEA methods.

Figure 1: Topographic features of the study area off the northeast United States redrawn from Ullman and Cornillon (1999). CH, NY, LI, and GB indicate the Cape Hatteras, New York, Long Island, and Georges Bank, respectively.

Figure 2: (a) AVHRR- SST for 0640 GMT 1 August 1995; (b) frontal segments obtained from CCA applied to the $3 \times 3$ median filtered SST field of panel a; (c) frontal segments obtained from SEA applied to the unfiltered SST field of panel a; (d) frontal segments following removal of all segments shorter than 10 pixels obtained from SEA applied to the unfiltered SST field of panel a; (e) frontal segments obtained from SEA applied to the $3 \times 3$ median filtered SST field of panel a, and; (f) frontal segments following removal of all segments shorter than 10 pixels obtained from SEA applied to the $3 \times 3$ median filtered SST field of panel a.

Figure 3: Monthly maps of SST front probability detected by (a) CCA applied to the $3 \times 3$ median filtered SST fields; (b) SEA applied to the unfiltered SST fields; (c) SEA applied to the unfiltered SST fields, with frontal segments shorter than 10 pixels removed, and; (d) SEA applied to the 3x3 median filtered SST fields, with frontal segments shorter than 10 pixels removed.

Figure 4: Monthly composite maps of SST gradient magnitude detected by (a) CCA applied to the $3 \times 3$ median filtered SST fields; (b) SEA applied to the unfiltered SST fields and; (c) SEA applied to the unfiltered SST fields, with frontal segments shorter than 10 pixels removed.

Figure 5: Along-track SST for 2 to 4 June 1995 obtained from the Oleander (black line) and AVHRR (gray line).

Figure 6: Histogram distribution in $20 \mathrm{~km}$ bins of front pixels detected along the Oleander track from (a) in-situ SST; (b) CCA applied to the $3 \times 3$ median filtered SST fields and; (c) SEA applied to the unfiltered SST fields, with frontal segments shorter than 10 pixels removed.

Figure 7: (a) SST for 1806 GMT 1 August 1995 with CCA detected fronts superimposed; (b) The same image with SEA detected fronts, obtained from the unfiltered field, superimposed and; (c) CCA detected fronts (blue) and SEA detected fronts (red) from the same SST field.

Figure 8: Error rate in detection of SST fronts by CCA and SEA (unfiltered) compared with the in situ data as a function of the gradient along the Oleander track. 


\section{References}

419 Belkin, I., Cornillon, P.C., 2003. SST fronts of the Pacific coastal and marginal seas.

$420 \quad$ Pacific Oceanography, 1 (2), 90-113.

421 Belkin, I.M., Cornillon, P.C., Sherman, K., 2009. Fronts in Large Marine Ecosystems.

422 Prog. Oceanogr. 81 (1-4), 223-236, doi:10.1016/j.pocean.2009.04.015.

423 Cayula, J.F., Cornillon, P., 1992. Edge detection algorithm for SST images. J. Atmos.

Ocean. Technol. 9 (1), 67-80.

425

Cayula, J.F., Cornillon, P., 1995. Multi-image edge detection for SST images. J. Atmos.

Ocean. Technol. 12 (4), 821-829.

427

Chang, Y., Shimada, T., Lee, M.A., Lu, H.J., Sakaida, F., Kawamura, K., 2006.

430 Chang, Y., Shieh, W.J., Lee, M.A., Chan, J.W., Lan, K.W., Weng, J.S., 2010. Fine-scale

433 Fedorov, K.N., 1986. The physical nature and dtructure of oceanic fronts. Lect. Notes 
438 Moore, J.K., Abbott, M.R., Richman, J.G., 1997. Variability in the location of the 439 Antarctic Polar Front $\left(90^{\circ}-20^{\circ} \mathrm{W}\right)$ from satellite sea surface temperature data. J. $440 \quad$ Geophys. Res. 102 (C13), 27825-27833.

441 Shimada, T., Sakaida, F., Kawamura, K., Okumura, T., 2005. Application of an edge 442 detection method to satellite images for distinguishing sea surface temperature fronts $443 \quad$ near the Japanese coast. Remote Sens. Environ. 98 (1), 21-34.

444 Ullman, D.S., Cornillon, P.C., 1999. Satellite-derived sea surface temperature fronts on 445 the continental shelf off the northeast U.S. coast. J. Geophys. Res. 104 (C10), $446 \quad 23459-23478$.

447 Ullman, D.S., Cornillon, P.C., 2000. Evaluation of front detection methods for 448 satellite-derived SST data using in situ observations. J. Atmos. Ocean. Technol. 17 $449 \quad(12), 171667-1675$.

450 Ullman, D.S., Cornillon, P.C., Shan, Z., 2007. On the characteristics of subtropical 451 fronts in the North Atlantic. J. Geophys. Res. 112 (C1), C01010, doi:10.1029/2006JC003601.

453 Vazquez, D.P., Atae-Allah, C., Luque-Escamilla, P.L., 1999. Entropic approach to edge 
455 Wang, D., Liu, Y., Qi, Y., Shi, P., 2001. Seasonal variability of thermal fronts in the 456 Northern South China Sea from satellite data. Geophys. Res. Lett. 28(20), $457 \quad 3963-3966$.

458 
459 Table 1:

\begin{tabular}{|ll|c|c|c|c|c|}
\hline \multicolumn{2}{|l|}{ ANOVA Table of DetectedFronts } \\
\hline Number of Fronts/Methods & & sum of square & of & Msan square & F & P \\
\hline In-situ, CCA and SEA * & Betwe9n & 252839.28 & 2 & 126419.64 & 76.51 & $3.79 \mathrm{E}-22$ \\
& vithin & 198274.88 & 120 & 1652.29 & & \\
In-situ and CCA & Betwe9n & 679.22 & 1 & 679.22 & 0.64 & 0.43 \\
& vvithin & 84952.83 & 80 & 1061.91 & & \\
In-situ and SEA * & Between & 200623.61 & 1 & 200623.61 & 111.4 & \\
& vithin & 144041.27 & 80 & 1800.52 & & \\
& Between & 177956.1 & 1 & 177956.1 & 84.97 & $3.28 \mathrm{E}-14$ \\
CCA and SEA * & vvithin & 167555.66 & 80 & 2094.45 & & \\
\hline
\end{tabular}

(*: Indicates there is a significant difference between methods.)

461 


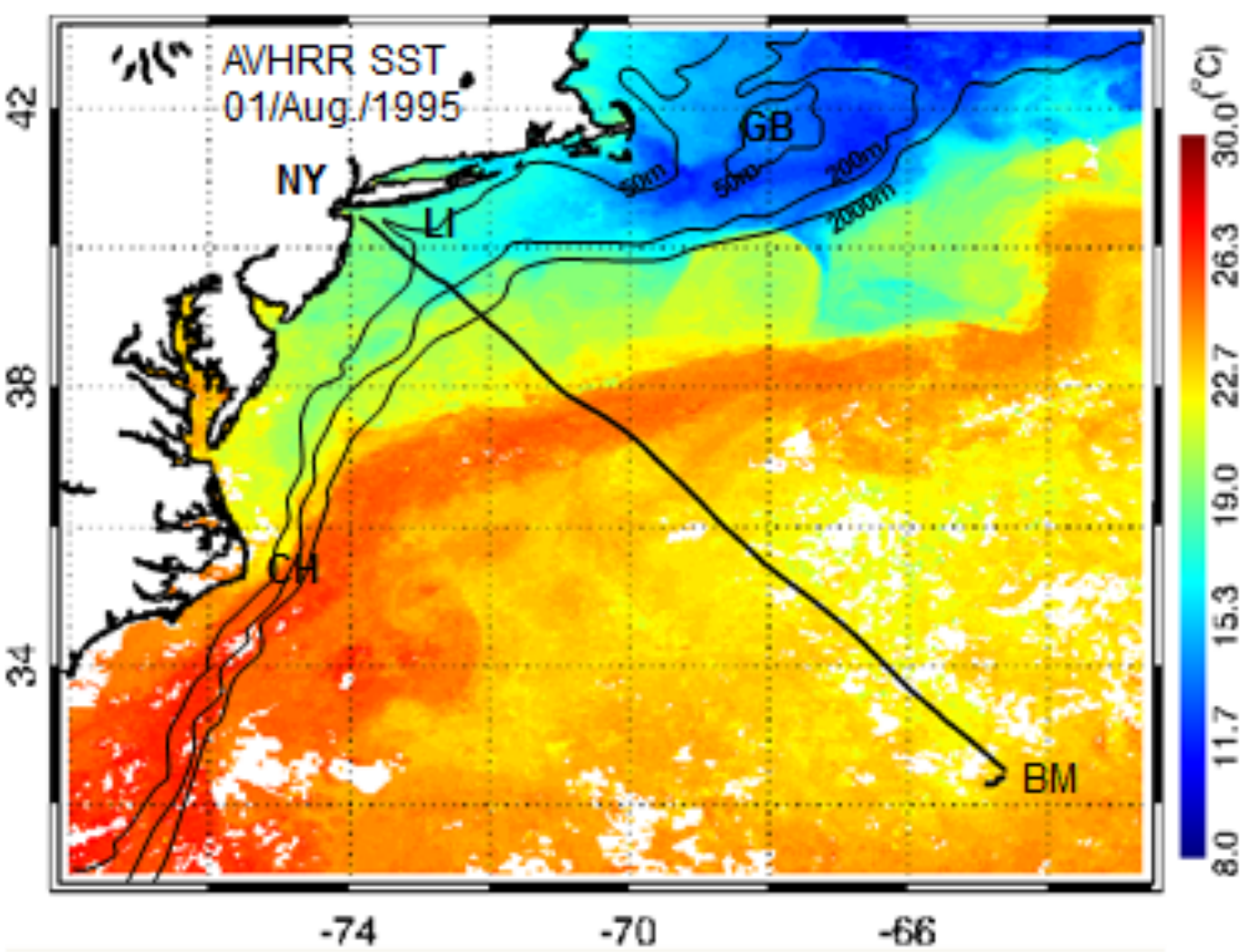

462

Figure 1.

464 

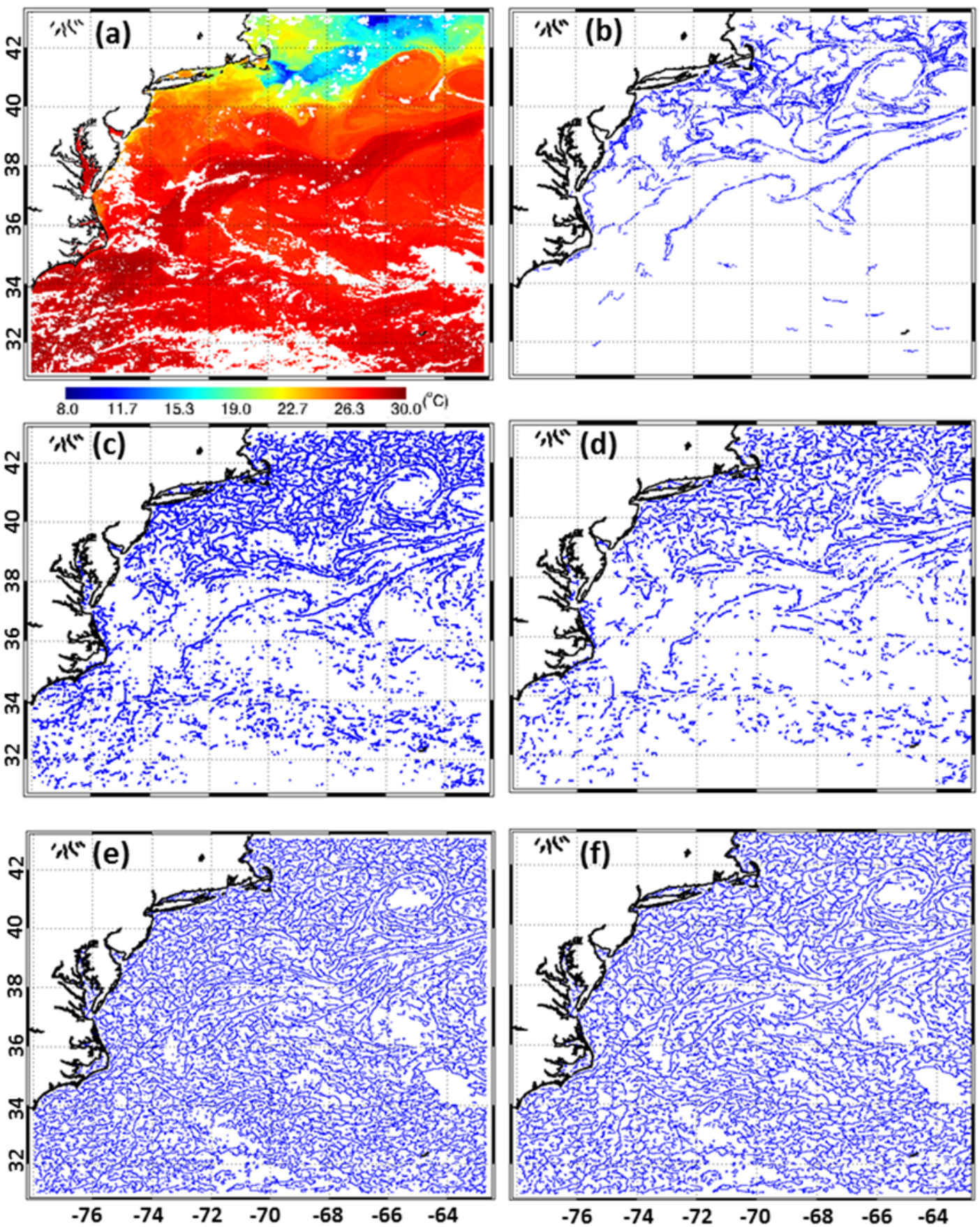

465

Figure 2.

467 

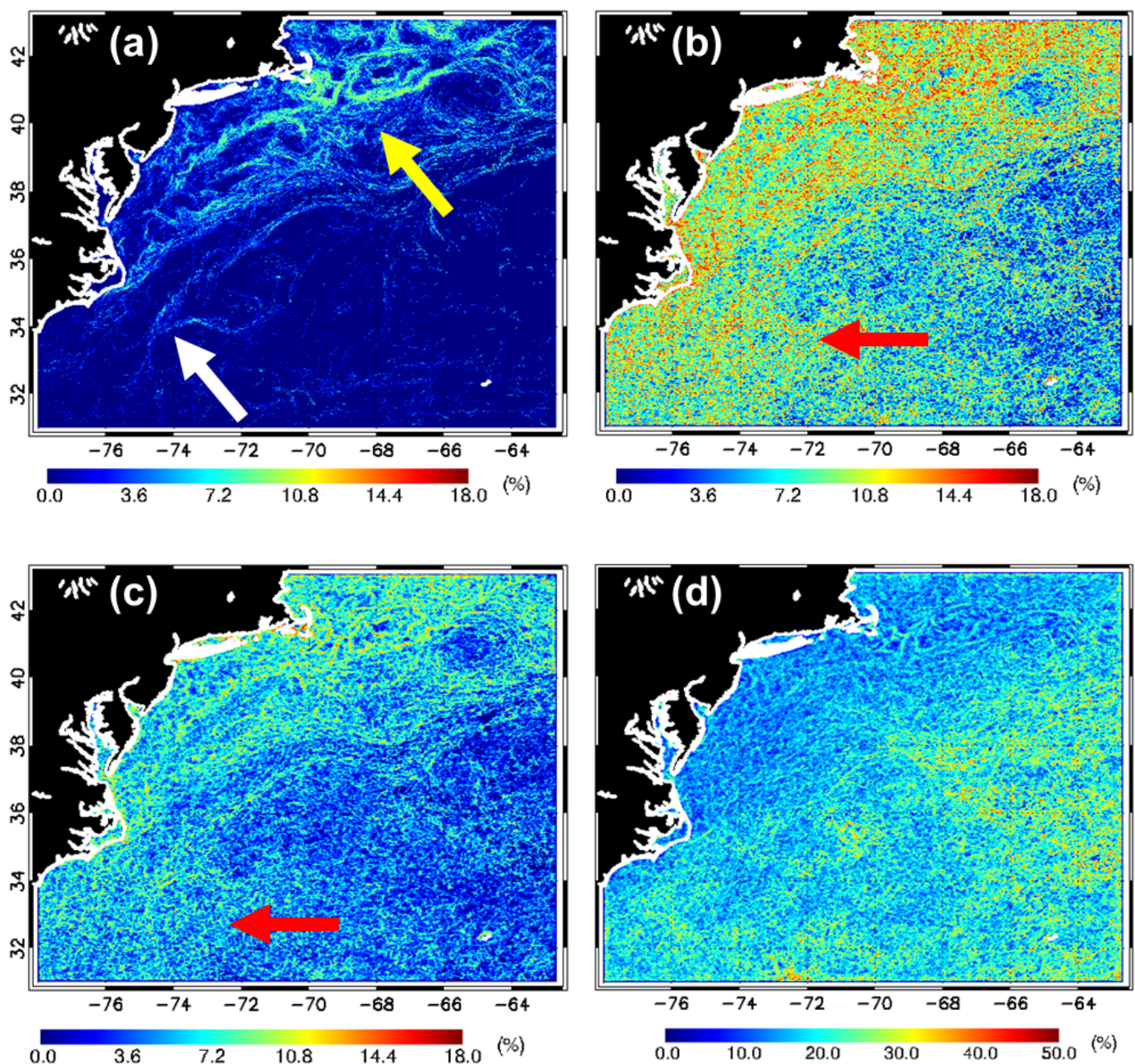

468

Figure 3.

470 


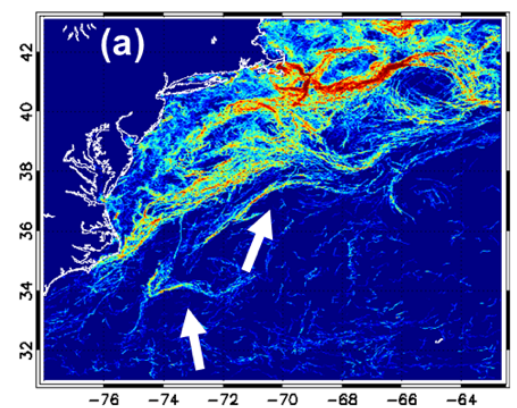

471

472 Figure 4.

473
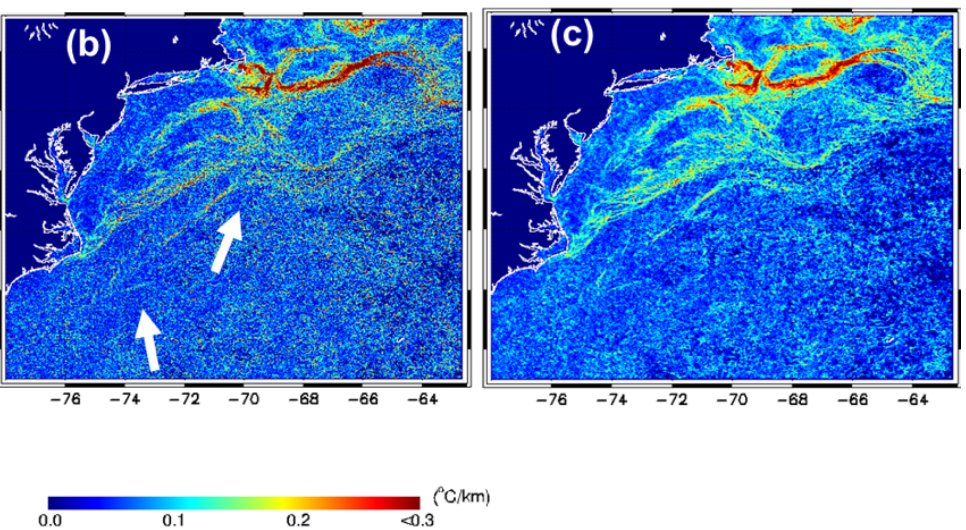


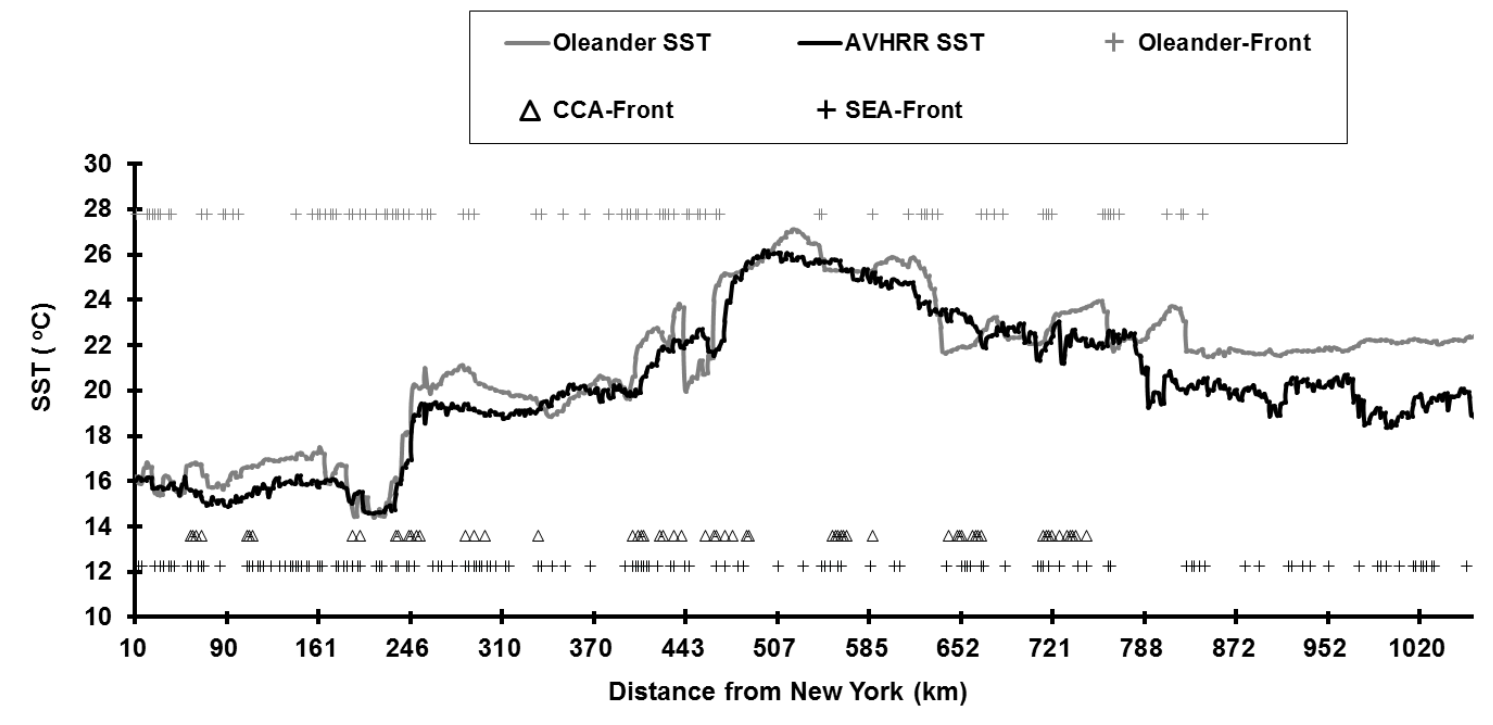

474

Figure 5.

476 

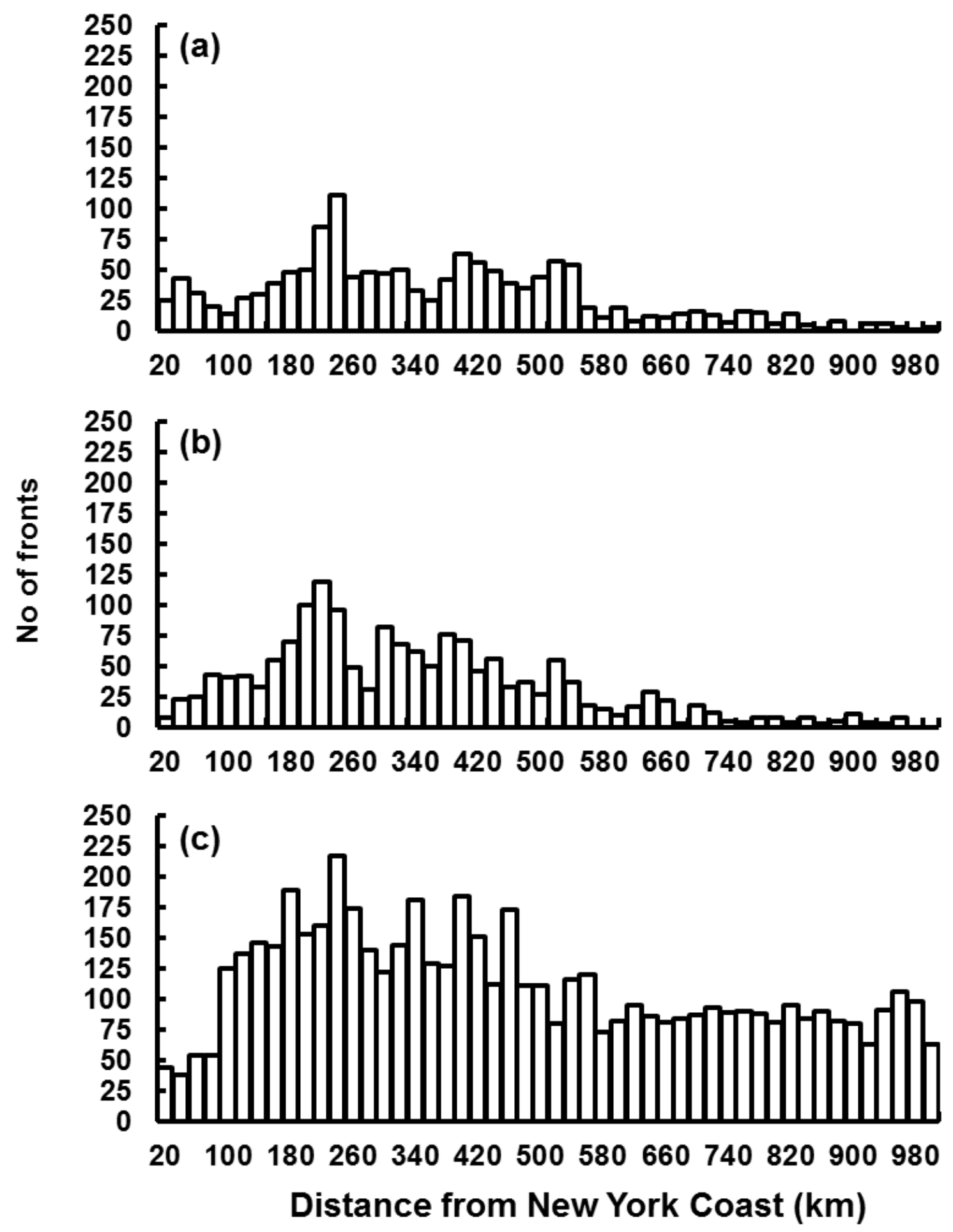

478 Figure 6. 

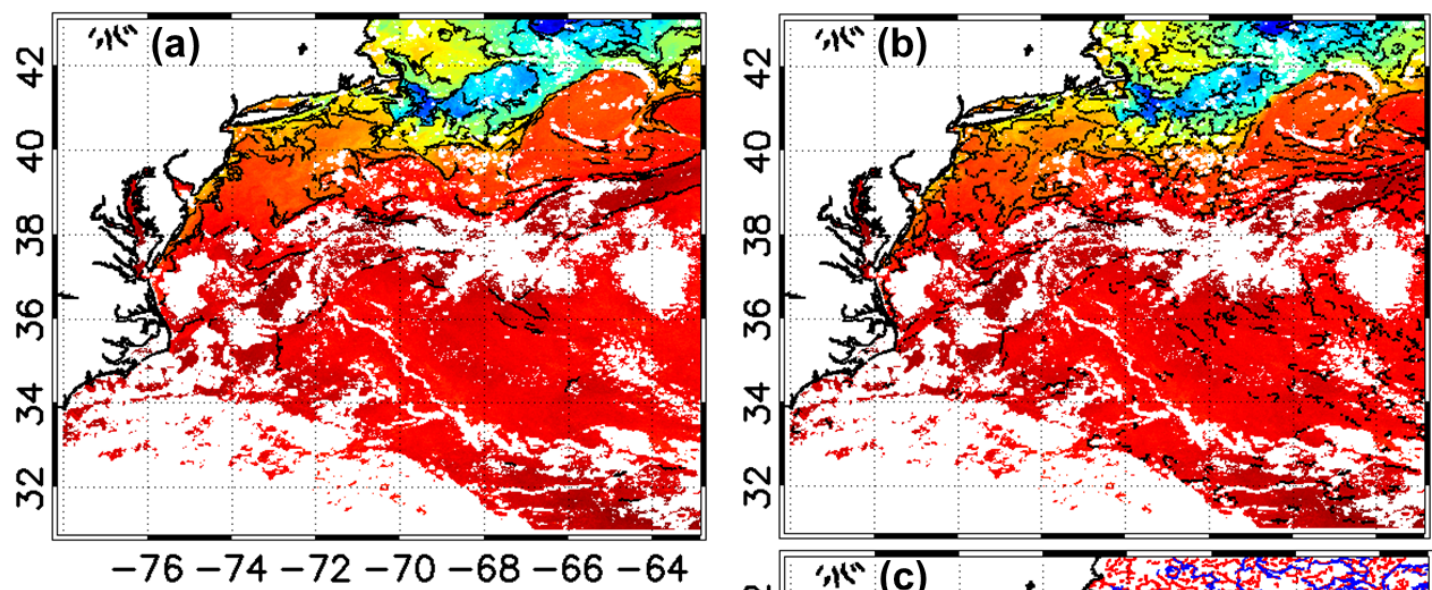

AVHRR of 08/01/1995, T=18:06

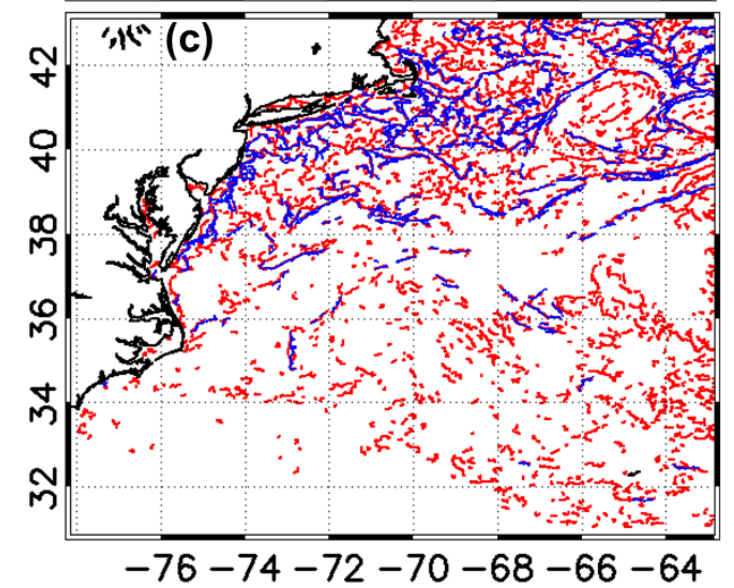

480

481 Figure 7.

482 


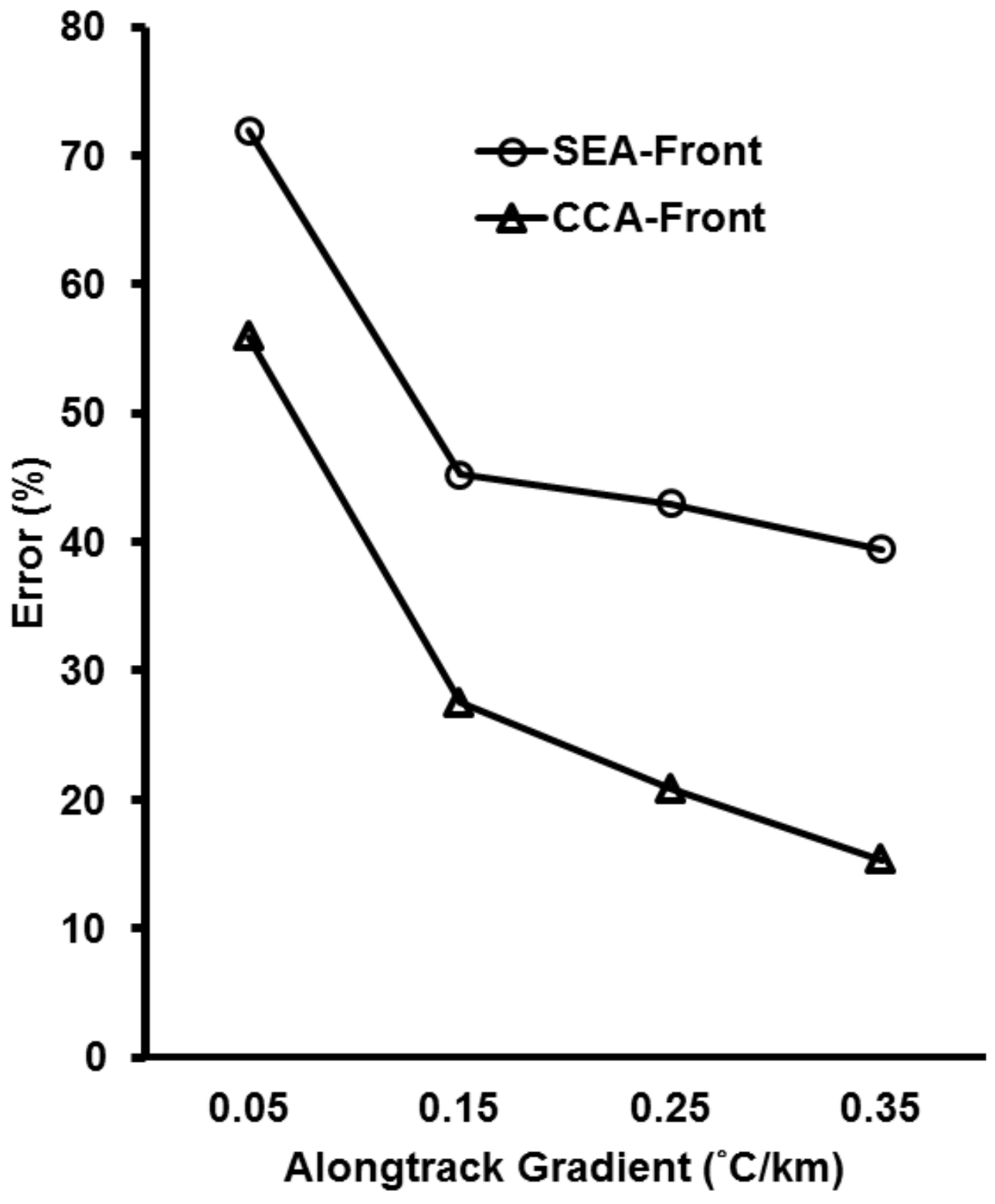

483

Figure 8. 